\title{
Proteínas do soro do leite: composição, propriedades nutricionais, aplicações no esporte e benefícios para a saúde humana
}

\author{
Whey protein: composition, nutritional properties, \\ appications in sports and benefits for human health
}

\author{
Fabiano Kenji HARAGUCHI \\ Wilson César de ABREU 2,3 \\ Heberth DE PAULA ${ }^{4}$
}

\section{RE S U M O}

As proteínas do soro do leite, também conhecidas como whey protein, são extraídas durante o processo de fabricação do queijo. Possuem alto valor nutricional, contendo alto teor de aminoácidos essenciais, especialmente os de cadeia ramificada. Também apresentam alto teor de cálcio e de peptídeos bioativos do soro. Pesquisas recentes demonstram sua grande aplicabilidade no esporte, com possíveis efeitos sobre a síntese protéica muscular esquelética, redução da gordura corporal, assim como na modulação da adiposidade, e melhora do desempenho físico. Estudos envolvendo a análise de seus compostos bioativos evidenciam benefícios para a saúde humana. Entre esses possíveis benefícios destacam-se seus efeitos hipotensivo, antioxidante e hipocolesterolêmico. Esta revisão buscou trabalhos que trazem avaliação das propriedades funcionais das proteínas do soro, tanto em humanos como em animais. Apesar das evidências apresentadas, novos estudos, assim como o desenvolvimento de novos alimentos enriquecidos com as proteínas do soro, com o intuito de facilitar seu consumo por grandes grupos populacionais, são necessários para verificar sua real eficácia.

Termos de indexação: alimentos fortificados; exercícios; proteínas do leite; suplementos dietéticos.

\section{A B S T R A C T}

The soluble proteins of milk, also known as whey protein, are extracted during the cheese manufacturing process. They have high nutritional value, with high levels of essential amino acids, especially branched chain

\footnotetext{
1 Bolsista, Programa de Mestrado, Núcleo de Pesquisas em Biologia, Universidade Federal de Ouro Preto. Rua Diogo de Vasconcelos, 122, 35400-000, Ouro Preto, MG, Brasil. Correspondência para/Correspondence to: S.K. HARAGUCHI. E-mail: <fabianokenji@gmail.com>

2 Departamento de Nutrição, Centro Universitário de Lavras. Lavras, MG, Brasil.

${ }^{3}$ Instituto de Ciências e Saúde, Curso de Nutrição, Centro Universitário de Formiga. Formiga, MG, Brasil.

4 Bolsista CNPq, Programa de Doutorado, Núcleo de Pesquisas em Biologia, Universidade Federal de Ouro Preto. Ouro Preto, MG, Brasil.
} 
amino acids. They also have a high level of calcium and whey bioactive peptides. Recent researches have shown their wide application for sports with possible effects on skeletal muscle protein synthesis, reduction of body fat, as well as adiposity modulation, and improved muscle performance. Researches involving the analysis of their bioactive compounds have also shown benefits to human health. Among these benefits, their hypotensive, antioxidant, and hypocholesterolemic effects stand out. This review has searched scientific articles that evaluate the functional properties of whey protein, both in humans and animals. Despite this evidence, new researches, as well as the development of new whey protein-enriched foods to increase their consumption by the population, are necessary to check their real effectiveness.

Indexing terms: food, fortified; exercise; milk proteins, dietary supplements.

\section{N T R O D U ÇÃ O}

Nas últimas décadas, numerosas pesquisas vêm demonstrando as qualidades nutricionais das proteínas solúveis do soro do leite, também conhecidas como whey protein. As proteínas do soro são extraídas da porção aquosa do leite, gerada durante o processo de fabricação do queijo. Durante décadas, essa parte do leite era dispensada pela indústria de alimentos. Somente a partir da década de 70, os cientistas passaram a estudar as propriedades dessas proteínas. Em 1971, o Dr. Paavo Airola, descreveu-as como parte importante no tratamento e prevenção de flatulências, prisão de ventre e putrefação intestinal ${ }^{1}$. Atletas, praticantes de atividades físicas, pessoas fisicamente ativas e até mesmo portadores de doenças, vêm procurando benefícios nessa fonte protéica. Evidências recentes sustentam a teoria de que as proteínas do leite, incluindo as proteínas do soro, além de seu alto valor biológico, possuem peptídeos bioativos, que atuam como agentes antimicrobianos, anti-hipertensivos, reguladores da função imune, assim como fatores de crescimento ${ }^{1-3}$

Evidenciar as principais características, componentes bioativos e os mecanismos de ação das proteínas do soro sobre a hipertrofia muscular, redução da gordura coporal e desempenho físico, assim como seus benefícios para a saúde humana, são os objetivos deste estudo.

\section{Proteínas do soro}

\section{Componentes e frações}

As proteínas do soro do leite apresentam uma estrutura globular contendo algumas pontes de dissulfeto, que conferem um certo grau de estabilidade estrutural. As frações, ou peptídeos do soro, são constituídas de: beta-lactoglobulina (BLG), alfa-lactoalbumina (ALA), albumina do soro bovino (BSA), imunoglobulinas (Ig's) e glicomacropeptídeos (GMP). Essas frações podem variar em tamanho, peso molecular e função, fornecendo às proteínas do soro características especiais $^{4-6}$. Presentes em todos os tipos de leite, a proteína do leite bovino contém cerca de $80 \%$ de caseína e $20 \%$ de proteínas do soro, percentual que pode variar em função da raça do gado, da ração fornecida e do país de origem ${ }^{1}$. No leite humano, o percentual das proteínas do soro é modificado ao longo da lactação, sendo que no colostro representam cerca de $80 \%$ e, na seqüência, esse percentual diminui para $50 \%{ }^{3}$.

A BLG é o maior peptídeo do soro (45,0\%-57,0\%), representando, no leite bovino, cerca de 3,2g/l. Apresenta médio peso molecular (18,4-36,8kDa), o que Ihe confere resistência à ação de ácidos e enzimas proteolíticas presentes no estômago, sendo, portanto, absorvida no intestino delgado. É o peptídeo que apresenta maior teor de aminoácidos de cadeia ramificada (BCAA), com cerca de 25,1\%. Importante carreadora de retinol (pró vitamina A) materno para o filhote, em animais, em humanos essa função biológica é desprezada, uma vez que a BLG não está presente no leite humano ${ }^{5}$.

Em termos quantitativos, a ALA é o segundo peptídeo do soro (15\%-25\%) do leite bovino e o principal do leite humano ${ }^{7}$. Com peso molecular de 14,2kDa, caracteriza-se por ser de fácil e rápida digestão. Contém o maior teor de triptofano (6\%) entre todas as fontes protéicas 
alimentares, sendo, também, rica em lisina, leucina, treonina e cistina ${ }^{4,8}$. A ALA é precursora da biossíntese de lactose no tecido mamário e possui a capacidade de se ligar a certos minerais, como cálcio e zinco, o que pode afetar positivamente sua absorção. Além disso, a fração ALA apresenta atividade antimicrobiana contra bactérias patogênicas, como, por exemplo, Escherichia coli, Staphylococcus aureus e Klebsiella pneumoniae ${ }^{3}$.

A BSA corresponde a cerca de $10 \%$ das proteínas do soro do leite. É um peptídeo de alto peso molecular $(66 \mathrm{kD})$, rico em cistina (aproximadamente $6 \%$ ), e relevante precursor da síntese de glutationa. Possui afinidade por ácidos graxos livres e outros lipídeos, favorecendo seu transporte na corrente sangüínea ${ }^{1,4,5}$.

As Ig's são proteínas de alto peso molecular (150 -1 000kDa). Quatro das cinco classes das Ig's estão presentes no leite bovino $(\lg G, \lg A$, $\lg M$ e $\lg \mathrm{E})$, sendo a $\lg \mathrm{G}$ a principal, constituindo cerca de $80 \%$ do total. No leite humano, a IgA constitui a principal imunoglobulina (>90\%). Suas principais ações biológicas residem na imunidade passiva e atividade antioxidante ${ }^{1,3-5,9}$.

O GMP $(6,7 \mathrm{kDa})$ é um peptídeo resistente ao calor, à digestão assim como a mudanças de $\mathrm{pH}$. Curiosamente, muitos autores não descrevem o GMP como um peptídeo do soro. Na verdade, o GMP é um peptídeo derivado da digestão da caseína-kapa, pela ação da quimosina durante a coagulação do queijo. Essa fração está presente em um tipo de proteína do soro, conhecida como whey rennet ${ }^{1,10}$. Apresenta alta carga negativa, que favorece a absorção de minerais pelo epitélio intestinal7 ${ }^{7}$ e, assim como a fração BLG, possui alto teor de aminoácidos essenciais (47\%).

As sub-frações ou peptídeos secundários das proteínas do soro são assim denominadas por se apresentarem em pequenas concentrações no leite. Compreendem as sub-frações: lactoferrina, beta-microglobulinas, gama-globulinas, lactoperoxidase, lisozima, lactolina, relaxina, lactofano, fatores de crescimento IGF-1 e IGF-2, proteoses-peptonas e aminoácidos livres. As subfrações lactoferrina, lisozima, lactoperoxidase, encontradas no leite humano, fornecem propriedades antimicrobianas importantes para o recém-nascido, assim como os fatores de crescimento IGF-I e IGF-II, que estão relacionados com o desenvolvimento do tubo digestivo.

As proteínas do soro podem exibir diferenças na sua composição de macronutrientes e micronutrientes, dependendo da forma utilizada para sua obtenção'. Segundo Salzano Jr¹, 100g de concentrado protéico do soro do leite possui, em média, 414kcal, $80 \mathrm{~g}$ de proteína, $7 \mathrm{~g}$ de gordura e $8 \mathrm{~g}$ de carboidratos. De acordo com Etzel ${ }^{10}$, a composição média de aminoácidos é de $4,9 \mathrm{mg}$ de alanina, 2,4mg de arginina, 3,8mg de asparagina, $10,7 \mathrm{mg}$ de ácido aspártico, $1,7 \mathrm{mg}$ de cisteína, 3,4mg de glutamina, 15,4mg de ácido glutâmico, 1,7mg de glicina, 1,7mg de histidina, $4,7 \mathrm{mg}$ de isoleucina, $11,8 \mathrm{mg}$ de leucina, $9,5 \mathrm{mg}$ de lisina, 3,1 mg de metionina, 3,0 mg de fenilalanina, 4,2mg de prolina, 3,9mg de serina, $4,6 \mathrm{mg}$ de treonina, $1,3 \mathrm{mg}$ de triptofano, $3,4 \mathrm{mg}$ de tirosina e $4,7 \mathrm{mg}$ de valina, por grama de proteína. Os BCAA perfazem $21,2 \%$ e todos os aminoácidos essenciais constituem $42,7 \%$. Segundo o autor, esses valores estão acima da média, quando comparados àqueles de outras fontes protéicas, fornecendo às proteínas do soro importantes propriedades nutricionais ${ }^{10}$. Em relação aos micronutrientes, possui, em média, 1,2mg de ferro, $170 \mathrm{mg}$ de sódio e $600 \mathrm{mg}$ de cálcio por $100 \mathrm{~g}$ de concentrado protéico1.

\section{Efeitos sobre o anabolismo muscular}

A diminuição da massa muscular esquelética está associada à idade e à inatividade física. Já está suficientemente comprovado que a manutenção ou o ganho de massa muscular esquelética, principalmente em pessoas idosas, contribui para uma melhor qualidade e prolongamento da vida. Exercícios físicos, principalmente os resistidos com pesos, são de extrema importância para impedir a atrofia e favorecer o processo de hipertrofia muscular11-13, melhorando a qua- 
lidade de vida dos indivíduos. Além disso, a nutrição exerce papel fundamental nesse processo Pessoas fisicamente ativas e atletas necessitam de maior quantidade protéica que as estabelecidas para indivíduos sedentários.

Segundo Lemon ${ }^{14}$, pessoas envolvidas em treinos de resistência necessitam de 1,2 a 1,4g de proteína por quilograma de peso ao dia, enquanto que atletas de força, 1,6 a 1,7g. ${ }^{1}$ por $\mathrm{kg}$ de peso/dia-1 ${ }^{-1}$, bem superior aos $0,8-1,0 \mathrm{~g} \cdot{ }^{-1}$ por $\mathrm{kg}$ de peso/dia dia ${ }^{-1}$, estabelecidos para indivíduos sedentários. A ingestão de proteína ou aminoácidos, após exercícios físicos, favorece a recuperação e a síntese protéica muscular ${ }^{14-16}$. Além disso, quanto menor o intervalo entre o término do exercício e a ingestão protéica, melhor será a resposta anabólica ao exercício. Esmarck et al. ${ }^{17}$ avaliaram o efeito da suplementação protéica $(10 \mathrm{~g}$ de proteínas provenientes do leite e da soja) em um grupo de 13 idosos, submetidos a programa de treinos resistidos com pesos, por 12 semanas Avaliando o ganho de força (repetições máximas e medidas de força dinâmica e isocinética) e a hipertrofia muscular (biópsia e ressonância magnética), observaram que o grupo que recebeu suplementação, logo após a realização da sessão de exercícios, apresentou um ganho significantemente maior de força e de hipertrofia muscular, quando comparado com o grupo que recebeu a suplementação protéica apenas 2 horas após a realização dos exercícios.

Existem diferentes vias pelas quais as proteínas do soro favorecem a hipertrofia muscular e o ganho de força, otimizando, dessa forma, o treinamento e o desempenho físico. A quantidade e o tipo de proteína ou de aminoácido, fornecidos após o exercício, influenciam a síntese protéica ${ }^{18}$. Estudos têm mostrado que somente os aminoácidos essenciais, especialmente a leucina, são necessários para estimular a síntese protéica ${ }^{19,20}$. van Loon et al. ${ }^{21}$ demonstraram que a ingestão de uma solução contendo proteínas do soro e carboidratos aumentou significantemente as concentrações plasmáticas de 7 aminoácidos essenciais, incluindo os BCAA, em comparação à caseína. Anthony et al. ${ }^{20}$ sugerem que a leucina participe no processo de iniciação da ativação da síntese protéica. Segundo os autores, a leucina tem um papel fundamental no processo de fosforilação de proteínas envolvidas na formação do complexo do fator de iniciação eucariótico $4 \mathrm{~F}$ (elF4F), que, por sua vez, inicia a tradução do RNA mensageiro (RNAm) para a síntese global de proteínas. A leucina atua, também, na cascata de reações que promove a fosforilação da proteína S6 cinase ribossomal (S6K1), que ativa a tradução de proteínas envolvidas no aparato de síntese protéica. Além disso, a leucina parece atuar na síntese protéica, por outros mecanismos diferentes e independentes dos citados acima.

O perfil de aminoácidos das proteínas do soro, principalmente ricas em leucina, pode, desta forma, favorecer o anabolismo muscular. Além disso, Ha \& Zamel ${ }^{9}$ destacam que o perfil de aminoácidos das proteínas do soro é muito similar ao das proteínas do músculo esquelético, fornecendo quase todos os aminoácidos em proporção similar às do mesmo, classificando-as como um efetivo suplemento anabólico. Em outro estudo, Burke et al. ${ }^{22}$ observaram, igualmente, significante ganho de massa muscular em adultos jovens suplementados com as proteínas do soro e submetidos a um programa de exercícios com pesos, quando comparado a um grupo não suplementado, corroborando a teoria do efeito das proteínas do soro sobre o ganho de massa muscular.

O conceito de proteínas com diferentes velocidades de absorção tem sido, recentemente, utilizado por profissionais e cientistas que trabalham com desempenho físico. Estudos demonstram que as proteínas do soro são absorvidas mais rapidamente que outras, como a caseína, por exemplo. Essa rápida absorção faz com que as concentrações plasmáticas de muitos aminoácidos, inclusive a leucina, atinjam altos valores logo após a sua ingestão ${ }^{23}$. Pode-se, dessa forma, hipotetizar que, se essa ingestão fosse realizada após uma sessão de exercícios, as proteínas do soro seriam mais eficientes no desencadeamento do processo de síntese protéica. Além de aumentar as concentrações plasmáticas 
de aminoácidos, a ingestão de soluções contendo as proteínas do soro aumenta, significativamente, a concentração de insulina plasmática ${ }^{24,25}$, o que favorece a captação de aminoácidos para o interior da célula muscular, otimizando a síntese e reduzindo o catabolismo protéico. Calbet \& MacLean ${ }^{25}$ avaliaram o efeito de quatro diferentes soluções, uma contendo somente $25 \mathrm{~g} /$ de glicose (C) e três contendo $25 \mathrm{~g} / \mathrm{l}$ de glicose e $0,25 \mathrm{~g} / \mathrm{kg}$ de peso corporal de três diferentes fontes protéicas: ervilhas (E), proteínas do soro (W) e leite integral (L) sobre as concentrações de insulina e aminoácidos. Observaram que, após 20 minutos da ingestão, a solução contendo as proteínas do soro provocou elevação na concentração plasmática de insulina de forma significante $(p<0,05)$. Essa elevação foi aproximadamente duas vezes maior que a observada com a solução contendo leite integral $(615$, com desvio-padrão $(\mathrm{dp})=104 \mathrm{pmol} / \mathrm{l}$ e $388, \mathrm{dp}=51 \mathrm{pmol} / \mathrm{l}$ para $\mathrm{W}$ e $\mathrm{L}$, respectivamente) e quatro vezes maior que a solução contendo somente glicose (C) (615, $\mathrm{dp}=104 \mathrm{pmol} / \mathrm{l}$ e $208, \mathrm{dp}=53 \mathrm{pmol} / / \mathrm{l}$ para $\mathrm{W}$ e C respectivamente). Após 80 minutos, a concentração de insulina em todos os grupos voltou aos valores iniciais. Observaram, também, que, após 20 minutos, a solução $\mathrm{W}$ provocou uma maior elevação na concentração plasmática de aminoácidos essenciais $(738, \mathrm{dp}=75 \mu \mathrm{mol} / \mathrm{l}$ para $1586, \mathrm{dp}=178 \mu \mathrm{mol} / \mathrm{l})$, principalmente os $\mathrm{BCAA}$, do que as outras soluções. $O$ aumento na concentração de BCAA, induzido pelas proteínas do soro, pode atuar também inibindo a degradação protéica muscular26.

Resumindo, seus benefícios sobre o ganho de massa muscular estão relacionados ao perfil de aminoácidos, principalmente da leucina (um importante desencadeador da síntese protéica), à rápida absorção intestinal de seus aminoácidos e peptídeos e à sua ação sobre a liberação de hormônios anabólicos, como, por exemplo, a insulina.

\section{Redução de gordura corporal}

O excesso de gordura corporal é considerado um problema de saúde pública há muitos anos. Estudos populacionais vêm mostrando que o excesso de peso é um problema, tanto para países desenvolvidos como para países em desenvolvimento ${ }^{27}$, sendo também fator de risco para o aparecimento de doenças crônicas ${ }^{28}$. Atletas e pessoas fisicamente ativas procuram, a todo custo, manter um percentual baixo de gordura corporal, seja com o objetivo de melhorar o desempenho físico ou apenas para o bem estar físico e mental. Vários trabalhos têm mostrado que as proteínas do soro favorecem o processo de redução da gordura corporal, por meio de mecanismos associados ao cálcio, e por apresentar altas concentrações de BCAA.

As proteínas do soro são ricas em cálcio (aproximadamente 600mg/100g). Diversos estudos epidemiológicos têm verificado uma relação inversa entre a ingestão de cálcio, proveniente do leite e seus derivados, e a gordura corporal ${ }^{29}$. Uma provável explicação seria que o aumento no cálcio dietético reduz as concentrações dos hormônios calcitrópicos, principalmente o 1,25 hidroxicolecalciferol $\left(1,25(\mathrm{OH})_{2} \mathrm{D}\right)$. Em altas concentrações, esse hormônio estimula a transferência de cálcio para os adipócitos. Nos adipócitos, altas concentrações de cálcio levam à lipogênese (síntese de novo) e à redução da lipólise. Portanto, a supressão dos hormônios calcitrópicos mediada pelo cálcio dietético, pode ajudar a diminuir a deposição de gordura nos tecidos adiposos ${ }^{29}$. As proteínas do soro poderiam oferecer uma vantagem sobre o leite como fonte de cálcio, em pessoas intolerantes à lactose, uma vez que grande parte dos suplementos à base de proteínas do soro é praticamente isenta de lactose, e pelo fato de essa proteína apresentar percentual de gordura menor que $2 \%$.

Estudos mostram que o alto teor de BCAA das proteínas do soro afeta os processos metabólicos da regulação energética, favorecendo o controle e a redução da gordura corporal. Em uma série de estudos, Layman, et al. ${ }^{30-32}$ mostraram que dietas com maior relação proteína/carboidratos são mais eficientes para o controle da glicemia e da insulina pós-prandial, favorecendo, dessa 
forma, a redução da gordura corporal e a preservação da massa muscular durante a perda de peso. Pesquisas têm reavaliado a contribuição dos BCAA para a homeostase glicêmica, pois esses aminoácidos são degradados nos tecidos musculares em proporção relativa à sua ingestão. Essa degradação aumenta as concentrações plasmáticas dos aminoácidos alanina e glutamina, que são transportadas para o fígado para a produção de glicose (gliconeogênese). Estudos sugerem que o ciclo alanina-glicose contribui em até $40 \%$ com a glicose endógena produzida durante o exercício, e em até $70 \%$ depois de um jejum noturno, estabilizando, portanto, a glicemia em períodos de jejum, e reduzindo a resposta da insulina após as refeições ${ }^{30}$. Por elevar as concentrações plasmáticas de BCAA ${ }^{17}$, a utilização de proteínas do soro nesses tipos de dietas seria vantajosa por reduzir a liberação de insulina pós-prandial e maximizar a ação do fígado no controle da glicemia, a partir da gliconeogênese hepática. Além disso, pelo fato de a leucina atuar nos processos de síntese protéica, altas concentrações desse aminoácido favorecem a manutenção da massa muscular durante a perda de peso ${ }^{30}$.

Para avaliar tais hipóteses, Layman et al. ${ }^{32}$ submeteram mulheres obesas ( $>15 \%$ do peso ideal) a dois tipos de dietas isocalóricas. Um grupo (Protéico) recebeu dieta com $1,5 \mathrm{~g} \cdot \mathrm{kg}^{-1} \cdot \mathrm{dia}^{-1} \mathrm{de}$ proteína, com 22,3g/dia de BCAA, sendo 9,9g/ dia de leucina, $40 \%$ das energias provenientes de carboidratos e $30 \%$ de lipídios. O outro grupo (Controle) recebeu dieta contendo $0,8 \mathrm{~g} \cdot \mathrm{kg}^{-1}$. dia-1 de proteína, com 12,3g/dia de BCAA, sendo 5,4g/ dia de leucina, $55 \%$ das energias provenientes de carboidratos e $30 \%$ de lipídios. Todos os voluntários foram precisamente controlados, quanto à ingestão das dietas e à realização de exercícios. Após 10 semanas, os autores observaram que o grupo Protéico apresentou valores estatisticamente maiores de glicemia em jejum e menores valores de glicemia pós-prandial. A dieta protéica gerou, também, melhor controle da insulina pós-prandial, com valores estatisticamente menores $(p<0,05)$. Em outro estudo, com o mesmo grupo de mulheres e aplicando os mesmos tipos de dietas, Layman ${ }^{30}$ observou que, após 16 semanas, a dieta protéica ocasionou uma perda significante de peso, gordura corporal e resultou uma menor perda de massa magra $(p<0,05)$. Em estudo anterior, realizado com ratos, Bouthegourd et al. ${ }^{33}$ observaram que, refeições pré-exercício, contendo as proteínas do soro, enriquecidas com a fração ALA, foram mais eficientes para a manutenção da massa muscular na perda de peso e mantiveram uma alta taxa de oxidação lipídica durante o exercício, similar às taxas observadas quando o exercício era realizado em jejum. Os autores sugerem que a captação intestinal e a composição de aminoácidos da proteína tiveram papel decisivo nos resultados observados. Porém, os mecanismos de ação não tinham sido esclarecidos. Possivelmente, a leucina e os outros BCAA tiveram efeito similiar aos observados no estudo de Layman $^{30}$ e Layman et al. ${ }^{32}$.

A colecistoquinina (CCK) e o peptídeo similar ao glucagon (GLP-1) são dois hormônios intestinais amplamente estudados. A liberação desses hormônios na corrente sanguínea ocorre em presença de macronutrientes no duodeno, produzindo efeito supressor do apetite ${ }^{34}$. Comparando as duas principais proteínas do leite, caseína e as proteínas do soro, Hall et al. ${ }^{35}$ estudaram seus efeitos sobre o apetite, percepção de fome, saciedade e hormônios gastrintestinais. Observaram que, quando os voluntários ingeriam uma solução contendo $48 \mathrm{~g}$ de proteínas do soro, 90 minutos antes da refeição, apresentavam uma redução significativa do apetite, da ingestão energética e aumento da saciedade, em comparação a um grupo que ingeriu a mesma solução contendo caseína. Essa percepção, apesar de subjetiva, estava relacionada às maiores concentrações sanguíneas de CCK e do GLP-1, geradas pela ingestão da solução contendo as proteínas do soro.

Em síntese, as proteínas do soro interferem positivamente na redução de gordura em função de seu alto teor de cálcio - e, conseqüentemente, pela atuação deste sobre o hormônio $1,25(\mathrm{OH})_{2} \mathrm{D}$ 
- e por agirem sobre os hormônios CCK e GLP-1. Sua utilização em dietas para perda de peso auxilia o controle da glicemia e a preservação da massa muscular devido às altas concentrações de BCAA.

\section{Efeitos sobre o desempenho físico}

Avaliar a ação de nutrientes e de substâncias ergogênicas sobre o desempenho físico torna-se, muitas vezes, uma tarefa difícil, principalmente quando se quer eleger o parâmetro para considerar qual nutriente, ou substância, teria efeito direto sobre o desempenho. Entretanto, se determinada substância exerce efeito sobre a composição corporal do atleta, por exemplo, possivelmente tal benefício afetaria, igualmente, seu desempenho. Estudos sugerem que o estresse oxidativo, produzido durante a atividade física, contribui para o desenvolvimento da fadiga muscular ${ }^{36}$, diminuindo o desempenho. Sabe-se, ainda, que a glutationa é o principal agente antioxidante, o qual depende da concentração intracelular do aminoácido cisteína para ser sintetizado. Lands et al. ${ }^{37}$ compararam o efeito de um suplemento à base de proteínas concentradas do soro (WPC) e da caseína (placebo) sobre o desempenho físico de adultos jovens, medido por meio de teste isocinético em bicicletas. Administrando $20 \mathrm{~g} / \mathrm{dia}$ de WPC durante três meses, o grupo suplementado com WPC apresentou um aumento de 35,5\% na concentração de glutationa. Além disso, os voluntários suplementados conseguiram gerar mais potência e maior quantidade de trabalho em testes de velocidade, sugerindo melhor rendimento. $O$ provável efeito estaria relacionado ao alto teor de cisteína das proteínas do soro, o que resultaria em aumento da concentração de glutationa, com subseqüente redução da disfunção muscular causada pelos agentes oxidantes. Esse foi o primeiro trabalho relacionando os efeitos das proteínas do soro aos parâmetros diretos do desempenho físico. Apesar dos resultados sugerirem tais benefícios, novos trabalhos são necessários para confirmar essa hipótese.

\section{Outros benefícios para a saúde humana}

O leite é, sem dúvida nenhuma, um alimento de extrema importância para o desenvolvimento humano. Entre suas inúmeras vantagens, a amamentação nos primeiros meses de vida é fundamental para o desenvolvimento, tanto do trato digestivo como da função imune, defendendo o bebê de bactérias, vírus e fungos patogênicos. Esses benefícios são atribuídos às proteínas encontradas no leite humano, inclusive as proteínas do soro.

Infelizmente, o leite humano está disponível apenas nos primeiros meses de vida. No entanto, desde que o homem passou a domesticar o gado bovino, há cerca de 6 mil anos, seu leite assumiu papel de destaque na nutrição humana, principalmente por ser uma excelente fonte de cálcio. Toba et al.$^{38}$ demonstraram que as proteínas do soro promovem a formação dos ossos em humanos, estimulando a proliferação e a diferenciação dos osteoblastos, aumentando a densidade mineral óssea e inibindo a reabsorção de cálcio.

A importância das proteínas do soro no controle da hipertensão tem sido foco de inúmeras pesquisas. As proteínas do leite possuem peptídeos que inibem a ação da enzima conversora de angiotensina (ECA), que, por sua vez, está envolvida no sistema renina-angiotensina. A ECA catalisa a formação de um potente vasoconstritor, a angiotensina II e inibe a ação da bradicinina, um vasodilatador. Os peptídeos da caseína (casocininas) e das proteínas do soro (lactocininas) apresentam potente efeito inibidor da ECA ${ }^{2,39}$. Apesar de muitos resultados serem observados in vitro, Pins \& Keenan ${ }^{40}$ avaliaram o efeito de um hidrolisado de proteínas do soro e observaram que sua utilização reduziu significativamente a pressão sangüínea, tanto sistólica como diastólica, via inibição da ECA e aumentou a atividade da bradicinina em humanos. Em outro estudo, Kawase et al. ${ }^{41}$ observaram que a administração de leite fermentado, enriquecido com WPC, diminuiu significativamente a pressão sanguínea sistólica em humanos, após oito semanas de estudo. Nesse mesmo estudo, observaram que os voluntários 
apresentavam significativa elevação da concentração de HDL colesterol, redução da concentração de triacilgleceróis e diminuição do risco cardíaco (Colesterol Total - HDL HDL).

Nos últimos anos, pesquisadores têm estudado os efeitos da alimentação e dos nutrientes sobre alterações do humor. O foco dessas pesquisas tem sido avaliar os efeitos da serotonina, um neurotransmissor produzido pelo cérebro que está diretamente relacionado às alterações de humor e ao estresse. Sob condições de estresse crônico, a produção exacerbada de serotonina pode resultar em depleção da mesma, via redução do triptofano, seu precursor, causando diminuição da sua atividade e, como conseqüência, alterações de humor e aparecimento da depressão.

A disponibilidade de triptofano na corrente sanguínea pode facilitar sua captação pelo cérebro e, dessa forma, favorecer a produção de serotonina. Diversas estratégias nutricionais têm sido investigadas com esse intuito. Entre essas, Markus et al. ${ }^{42}$ observaram, em pacientes submetidos ao estresse, que a administração de uma dieta enriquecida com a fração ALA (rica em triptofano) aumentou em $48 \%$ a relação plasmática Triptofano/Aminoácidos neutros (TRP/AAN), em comparação a uma dieta placebo, composta de caseína, favorecendo, o acesso do TRP ao cérebro. O aumento na disponibilidade de TRP estimulou a produção de serotonina, melhorou o humor e reduziu a depressão dos sujeitos em estudo, de forma significativa. Apesar de contraditório às observações de que a administração de precursores da serotonina aumenta as concentrações de cortisol, o aumento na concentração de triptofano reduziu as concentrações desse hormônio. Nesses indivíduos, a atividade da serotonina pode melhorar a adaptação ao estresse, contribuindo para a redução do cortisol. Segundo esses autores, diferentes vias metabólicas estão envolvidas na adaptação ao estresse, iniciando e finalizando a atividade do eixo adrenocortical, não sendo a neurotransmissão serotonérgica um mecanismo único. Conseqüentemente, a capacidade de adaptação ao estresse pode acompanhar uma redução da resposta do cortisol e melhorar o humor. As observações pertinentes ao cortisol divergem das alterações observadas em atletas submetidos a atividades aeróbias extenuantes, nos quais o aumento da relação plasmática TRP/AAN, resultante da diminuição na concentração de aminoácidos neutros, eleva a produção de cortisol, desencadeando um processo conhecido como fadiga central ${ }^{43}$. Em outro estudo, Markus et al. ${ }^{8}$ observaram que a mesma dieta melhorava o desempenho cognitivo em pacientes de mesmo perfil, via aumento do TRP no cérebro e da atividade da serotonina.

Inúmeras pesquisas vêm demonstrando outras propriedades nutricionais e funcionais das proteínas do soro. Estudos envolvendo a ação da fração GMP na prevenção da cárie ${ }^{6}$, na absorção de zinco ${ }^{44}$, além de sua extensa aplicação na indústria de alimentos, como, por exemplo, na produção de fórmulas infantis, panificação, embutidos, sorveteria ${ }^{1,4}$, têm sido realizados. Entretanto, sua disponibilidade para o consumo populacional é ainda pequena. As proteínas do soro são, geralmente, encontradas sob a forma de pó em suplementos alimentares. A maioria dos fabricantes brasileiros utiliza, no entanto, proteínas produzidas fora do país, dificultando o conhecimento sobre seu processo de fabricação, o que torna, muitas delas, de qualidade duvidosa, além de onerar o custo final de consumo. No Brasil, sua produção é ainda limitada, sendo o Instituo de Tecnologia de Alimentos (ITAL) de Campinas, São Paulo, um dos pioneiros na produção de concentrados protéicos do soro, porém sua utilização se restringe a pesquisas científicas ${ }^{45}$.

\section{O N CLUS Ã O}

As proteínas solúveis do soro do leite apresentam um excelente perfil de aminoácidos, caracterizando-as como proteínas de alto valor biológico. Possuem peptídeos bioativos do soro, que conferem a essas proteínas diferentes propriedades funcionais. Os aminoácidos essen- 
ciais, com destaque para os de cadeia ramificada, favorecem o anabolismo, assim como a redução do catabolismo protéico, favorecendo o ganho de força muscular e reduzindo a perda de massa muscular durante a perda de peso. $\mathrm{O}$ alto teor de cálcio favorece a redução da gordura corporal, por mecanismo associado ao hormônio 1,25 $(\mathrm{OH})_{2} \mathrm{D}$. Melhoram, também, o desempenho muscular, por elevarem as concentrações de glutationa, diminuindo, assim, a ação dos agentes oxidantes nos músculos esqueléticos. Exercem papel importante na saúde humana, como, por exemplo, no controle da pressão sanguínea e como agente redutor do risco cardíaco. Além disso, as proteínas do soro têm sido muito utilizadas pela indústria de alimentos, em diferentes áreas. Novos estudos in vivo e epidemiológicos são necessários para avaliar a real eficácia de seus componentes. O enriquecimento de alimentos com as proteínas do soro, como bebidas, por exemplo, facilitaria seu consumo e o estudo em grandes grupos populacionais.

\section{REFERÊ NCIAS}

1. Salzano Jr I. Nutritional supplements: practical applications in sports, human performance and life extension. Symposium series 007; São Paulo; 1996-2002. p.75-202.

2. Groziak SM, Miller GD. Natural bioactive substances in milk and colostrum: effects on the arterial blood pressure system. Brit J Nutr. 2000; 84(6):119-25

3. Lönnerdal B. Nutritional and physiologic significance of human milk proteins. Am J Clin Nutr. 2003; 77(6):1537-43.

4. Kinsella JE, Whitehead DM. Proteins in whey: chemical, physical and functional properties. Adv Foods Nutr Res. 1989; 33:343-438.

5. De Wit JN. Nutritional and functional characteristics if whey proteins in foods products. J Dairy Sci. 1998; 81(3):597-608.

6. Aimutis WL. Bioactive properties of milk proteins with particular focus on anticariogenesis. J Nutr. 2004; 134(4):989s-95s.

7. Shannon LK, Chatterton D, Nielsen K, Lönnerdal B. Glycomacropeptide and alfa-lactoalbumin supplementation of infant formula affects growth and nutritional status in infant rhesus monkeys. Am J Clin Nutr. 2003; 77(5):1261-8.
8. Markus CR, Oliver B, DE Haan EHF. Whey Protein rich in alfa-lactoalbumin increases the ratio of plasma tryptophan to the sum of the other large neutral amino acids and improves cognitive performance in stress-vulnerable subjects. Am J Clin Nutr. 2002; 75(6):1051-6.

9. Ha E, Zemel MB. Functional properties of whey, whey components, and essential amino acids: mechanisms underlying health benefits for active people. J Nutr Biochem. 2003; 14(5):251-58.

10.Etzel MR. Manufacture and use of dairy protein fractions. J Nutr. 2004; 134(4):996s-1002s.

11. Phillips SM, Tipton KD, Ferrando AA, Wolfe RR. Resistance training reduces the acute exercise-induced increase in muscle protein turnover. Am J Physiol End Met. 1999; 276(1):E118-24.

12. Yarasheski KE, Pak-Loduca J, Hasten DL, Obert KA, Brown MB, Sinacore DR. Resistance exercise training increases mixed muscle protein synthesis rate in frail woman and men $>76 \mathrm{yr}$ old. Am J Physiol. 1999; 277(1):E118-25.

13. Hasten DL, Pak-Loduca J, Obert KA, Yarasheski KE. Resistance exercise acutely increases $\mathrm{MHC}$ and mixed muscle protein synthesis rates in 78-84 and 23-32 yrs old. Am J Physiol End Met. 2000; 278(4):E620-6.

14. Lemon PWR. Effects of exercise on dietary protein requirements. Int J Sports Nutr. 1998; 8(4): 426-47

15. Ivy JL, Goforth Jr HW, Damon BM, McCauley TR, Parsons EC, Price TB. Early postexercise muscle glycogen recovery is enhanced with a carbohydrate-protein supplement. J Appl Physiol. 2002; 93(4):1337-44.

16. Børshein E, Aarsland A, Wolfe, RR. Effect of an amino acids, protein, and carbohydrate mixture in net muscle protein balance after resistance exercise. Int J Sports Nutr Exer Metab. 2004; 14(3):255-71.

17. Esmarck B, Andersen JL, Olsen S, Richter EA, Mizuno M, Kjaer M. Timing of postexercise protein intake is important for muscle hypertrophy with resistance training in elderly humans. J Physiol. 2001; 535(1):301-11.

18. Wolfe RR. Protein supplements and exercise. Am J Clin Nutr. 2000; 72(2):551s-7s.

19. Kimball SC. Regulation of global and specific mRNA translation by amino acids. J Nutr. 2002; 132(5):883-6.

20. Anthony JC, Anthony TG, Kimball SR, Jefferson LS. Signaling pathways involved in translation control of protein synthesis in skeletal muscle by leucine. J Nutr. 2001; 131(3):856s-60s. 
21.van Loon LJC, Saris WHM, Verhagen H, Wagenmakers JM. Plasma insulin responses after ingestion of different amino acid or protein mixtures with carbohydrate. Am J Clin Nutr. 2000; 72(1):96-105.

22. Burke DG, Chilibeck PD, Davison KS, Candow DG, Farthing J, Smith-Palmer T. The effect of whey protein supplementation with and without creatine monohydrate combined with resistance training on lean tissue mass and muscle strength. Int J Sports Nutr Exe Met. 2001; 11(3):349-64.

23. Dangin M, Boirie $Y$, Garcia-Rodenas C, Gachon $P$, Fauquant J, Callier $\mathrm{P}$, et al. The digestion rate of protein is an independent regulating factor of postprandial protein retention. Am J Physiol End Met. 2001; 280(2):E340-E8.

24. Zawadzki KM, Yaspelkis BB III, Ivy JL. Carbohydrate-protein complex increased the rate of muscle glycogen storage after exercise. J Appl Physiol. 1992; 72(5):1854-9.

25. Calbet JAL, MacLean DA. Plasma glucagon and insulin responses depend on the rate of appearance of amino acids after ingestion of different protein solutions in humans. J Nutr. 2002; 132(8):2174-82.

26. Werustsky CA. Inibição da degradação protéica muscular em atletas pela suplementação de aminoácidos. Nutrição Enteral e Esportiva. Rio de Janeiro; 1993. 6:4-7.

27. Popkin BM. The nutrition transition and its health implications in lower-income countries. Publ Health Nutr. 1998; 1(1):5-21

28. Fontaine KR, Faith MS, Allison DB, Cheskin LJ. Body weight and health care among woman in the general population. Arch Farm Med. 1998; 7(4):381-4

29. Zemel MA. Role of calcium and dairy products in energy partitioning and weight management. Am J Clin Nutr. 2004; 79(5):907s-12s

30. Layman DK. The role of leucine in weight loss diets and glucose homeostasis. J Nutr. 2003; 133(1): 261-7.

31. Layman DK, Baum Jl. Dietary protein impact on glycemic control during weight loss. J Nutr. 2004; 134(4):968s-73s.

32. Layman DK, Shiue H, Sather C, Erickson D, Baum J. Increased dietary protein modifies glucose and insulin homeostasis in adult woman during weight loss. J Nutr. 2003; 133(2):405-10

33. Bouthegourd JCJ, Roseau SM, Makarios-Lahhan L, Leruyet PM, Tomé DG, Even PC. A preeexercise alfa-lactalbumin-enriched whey protein meal preserves lipid oxidation and decreases adiposity in rats. Am J Physiol End Met. 2002; 283(3): E565-E72.

34. Graaf C, Blom WAM, Smeets AM, Stafleu A, Hendriks FJ. Biomarkers of satiation and satiety. Am J Clin Nutr. 2004; 79(6):946-61.

35. Hall WL, Millward DJ, Long SJ, Morgan LM. Casein and whey exert different effects on plasma amino acids profiles, gastrointestinal hormone secretion and appetite. Brit J Nutr. 2003; 89(2):239-48.

36. Pedersen BK, Hoffman-Goetz L. Exercise and the immune system: regulation, integration and adaptation. Physiol Rev. 2000; 80(3):1055-81.

37. Lands LC, Grey VL, Smoutas AA. Effect of supplementation with cysteine donor on muscular performance. J Appl Physiol. 1999; 87(4):1381-5.

38. Toba Y, Takada, Y, Matsuoka Y, Morita Y, Motouri M, Iría $T$, et al. Milk basic protein promotes bone formation and suppresses bone resorption in health adult men. Biosci Biotechnol Biochem. 2001; 65(4):1353-57.

39. Fitzgerlad RJ, Murray BA, Walsh DJ. Hypotensive peptides from milk protein. J Nutr. 2004; 134(4):980s-8s.

40. Pins JJ, Keenan JM. The effects of a hydrolyzed whey protein supplement (Biozate ${ }^{\circledR} 1$ ) on ACE activity and bradykinin. In: Proceeding of 64th Annual Scientific Sessions of the American Diabetes Association 2004; Orlando, Florida.

41. Kawase M, Hashimota $H$, Hosoda M, Morita $H$, Hosono A. Effects of administration of fermented milk containing whey protein concentrate to rats and healthy men on serum lipids and blood pressure. J Dairy Sci. 2000; 83(2):255-63.

42. Markus CR, Oliver, B, Panhuysen GEM, der Gusten $\mathrm{JV}$, Alles MS, Tuiten $\mathrm{A}$, et al. The bovine protein alfa-lactalbumin increases the plasma ratio of tryptophan to the other large neutral amino acids, and in vulnerable subjects raises brain serotonin activity, reduces cortisol concentration, and improves mood under stress. Am J Clin Nutr. 2000; 71(6):1536-44.

43. Rossi L, Tirapegui J. Aspectos atuais sobre exercício físico, fadiga e nutrição. Rev Paul Educ Fis. 1999; 13(1):67-82.

44. Lönnerdal B. Dietary factors influencing zinc absorption. J Nutr. 2000; 130(5):1378s-83s.

45. Borges PFZ. Produção de concentrados de proteínas de leite bovino: composição e valor nutritivo. Braz J Food Tecnol. 2001; 4(1):1-8.

Recebido em: 21/12/2004

Versão final reapresentada em: 19/10/2005 Aprovado em: 7/11/2005 